\title{
Editorial
}

\section{To our readers}

The first year has passed since Diabetologia moved from Düsseldorf to Uppsala. Meanwhile, the editorial staff have warmed up and we are now ready to sum up our experiences so far, and even define some of the future goals of the journal. The Editor-in-Chief has learned to appreciate the relief of having no spare time to worry about and has increased considerably in muscle strength from carrying piles of manuscripts whenever he gets one of these rare opportunities to leave his desk. New and interesting insights into the depths of human souls have been gained from the exchange with the authors, the readers and the referees. All in all it has been an instructive, exciting and exhausting year which none of us would have missed for the world!

The life of a scientific journal rests on four legs: the authors, the referees, the readership and the publisher. The editorial staff, with the aid of the referees, is the filter through which each manuscript must pass before it can be published. The inflow of manuscripts to Diabetologia has continued to be high and, indeed, seems to have reached a record figure of about 500 for 1989. However, Diabetologia is a rather slim lady, and has so far been able to accomodate only about 125 articles per annual volume. By necessity the acceptance rate therefore is no higher than about $25 \%$, which creates a rather difficult problem of selection for the Editor-in-Chief. If, by chance, any author of a rejected manuscript should still be interested in reading these lines, please be aware that competition for publication space is tough in our journal and your contribution might have been turned down just for priority reasons. The criteria we try to apply in the selection process are almost exclusively scientific merit and originality, although in exceptional cases manuscripts may be turned down for other reasons. Lack of obediance to ethical rules is one such example which applies to both human and animal experiments. The fact remains, however, that many potentially interesting manuscripts cannot be accepted for publication in Diabetologia because of lack of space. We will do our best to persuade our publisher to increase the space for publication and hope that authors from all over the world will continue to submit their papers to us.

It goes without saying that no editor of a scientific journal can deal in a knowledgeable way with more than a small fraction of all the information submitted for publication. The peer review system for manuscripts, therefore, is indispensible and I feel a sincere gratitude to our hundreds of referees for their willingness and patience and for the expertise they so generously share with us. As I have said before, referees, like certain other people in the field of diabetology, can be subdivided into fast responders, slow responders and non-responders. Both editors and authors have to live with this fact and in my experience the two latter categories represent only a small minority. Some frustration, may nevertheless, be felt occasionally when proliferative authors seem to completely forget a moderate request to use a fraction of their precious time for reviewing manuscripts by other authors. Anyhow, these few exceptions cannot conceal the fact that the contribution by our referees to the quality of Diabetologia is overwhelming.

The readers are those who finally judge whether the combined efforts by authors, editor and publisher to present a scientific paper in print were actually worthwhile. A long-term measure of this judgement would be the number of readers and, for a scientific journal, also the impact factor. Diabetologia at present has a wide circulation from a geographical point of view although the actual number of subscribers could probably still be increased. An increase in this number would not only enhance the distribution of new facts about diabetes, but also reduce the subscription fee. In contrast, the most recent impact factor, that for 1987, ranked Diabetologia as second among diabetes-oriented journals in the world. Although the impact factor is a rather blunt instrument it nevertheless indicates a high frequency of citations for articles appearing in the journal.

What then are the policies and goals of Diabetologia as of 1990 , as seen from the horizon of the editorial office? 
With regard to the content we would like to maintain a fair balance between basic and clinical research. By tradition Diabetologia publishes work on all aspects of diabetes and we feel that cross-fertilization between clinical and basic research is of particular significance for the advancement of knowledge in this field. The feed-back from the readership has so far been mainly confined to our Letters to the Editor section. As from this issue a new section called "For debate" will be introduced, and we invite our readers to use this space to bring up controversies and problems of general interest for discussion. We are aware that this may to some extent restrict the space for original publications but hope that the stimulus for exchange of opinions will outweigh the possible draw-back. Views and opinions on a debate article, if not solicited, will be pub- lished as Letters to the Editor at the discretion of the Editor-in-Chief.

For 1990 it will be the ambition of the editorial staff to find new ways of increasing the circulation of the journal and to expand the space for publication. Fulfilling this task, however, requires the production of a journal of highest possible scientific quality. In our efforts to reach this goal we anticipate the continuous support of our reader, authors, referees and publisher.

Happy New Year to all of you!

Claes Hellerström, Uppsala

January 1, 1990 